\title{
Feasibility study on the inductive fault current limiting cable
}

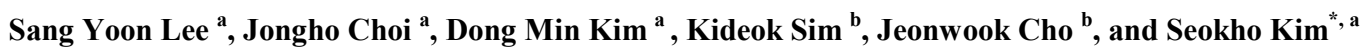 \\ a Changwon National University, Changwon, Korea \\ ${ }^{\mathrm{b}}$ Korea Electrotechnology Research Institute, Changwon, Korea
}

(Received 19 August 2013; revised or reviewed 24 September 2013; accepted 25 September 2013)

\begin{abstract}
Fault current limiting (FCL) cable is a kind of superconducting cable which has a function of limiting the fault current at the fault of power grid. The superconducting cable detours the fault current through its stabilizer to keep the temperature as low as possible. On the other hands, the FCL cable permits the temperature rise within some acceptable limit and the fault current is limited by the consequent increase of the resistance of superconducting cable. This kind of FCL cable is called 'resistive FCL cable' because it uses resistive impedance to limit the fault current. In this paper, we suggest a novel concept of FCL cable, which is named as 'inductive FCL cable'. The inductive FCL cable is similar as the magnetic shielding fault current limiter in its operating mechanism. The magnetic field of superconducting cable is almost perfectly shielded by the induced current at the shielding layer during its normal operation. However, at the fault condition, quench occurs at the shielding layer by the induced current higher than its critical current and the magnetic field is spread out of the shielding layer. It will induce additional inductive impedance to the superconducting cable and the inductive impedance can be increased more by installing some material with high magnetic susceptibility around the superconducting cable. We examined the feasibility of inductive FCL cable with simple elemental experiments. The current limiting performance of inductive FCL cable was estimated considering an arbitrary power grid and its fault condition.
\end{abstract}

Keywords : Superconducting Fault Current Limiting Cable, inductive impedance, quench

\section{1. 서 론}

초전도 선재 및 응용분야의 기술 발전으로 인하여 전기 에너지의 생산 및 저장 등 전반적인 전력 계통에 많은 변화들을 가져오고 있다. 특히 초전도 케이블의 혁신적인 성장으로 대용량 송배전이 가능하게 되었다[1].

그러나, 최근 계통부하의 증가와 함께 점차적으로 그 크기가 증가하고 있는 사고전류는 주변 기기 및 설비에 악 영향을 미칠 수 있다[2]. 일반적으로, 사고 발생 시 차단기가 동작하여 사고 전류를 차단하지만 그 용량에는 한계가 있고, 차단시간도 0.1 초 이상의 긴 시간이 소요되어 전력기기의 수명단축 및 고장 등이 발생하게 된다. 따라서, 차단기 동작이전에 사고전류를 제한할 수 있는 초전도한류기 (SFCL : Superconducting Fault Current Limiter)의 도입이 필수적이다.[3] 초전도한류기의 경우 기존 회로의 변경 없이 차단기의 용량을 $3 \sim 5$ 배 이상 증대시키는 효과를 내는 등 그 파급 효과가 클 것으로 예상되어 미국, 일본, 유럽 등지에서 활발한 연구가 진행되고 있다[4],[5].

따라서, 대도시나 부하가 밀집된 장소에서는 대용량 전력 수송과 사고 전류 제한의 목적을 동시에 달성할 수 있는 초전도 전력기기의 개발이 필요하다. 초전도 한류 케이블은 사고 전류를 억제하는 한류기의 특성을 초전도 케이블에 적용시킨 것으로 기존의 한류기와는 다르게 별도의 설치 공간이 필요하지 않기 때문에 공간의 제약을 받지 않는 것이 장점이다.

일반적으로, 초전도 케이블은 정상 상태에서 많은 전류를 흘릴 수 있지만, 계통 사고 시에는 사고전류를 낮은 저항을

* Corrresponding author: hcri@knu.ac.kr
갖는 케이블 포머로 우회함으로써 초전도 케이블을 보호할 수 있도록 설계된다. 즉, 사고시에도 초전도 케이블의 임피던스 증가를 최대한 억제시킴으로써 초전도 케이블 자체의 온도 상승을 줄이는 방향으로 설계되어 왔다[6]. 그러나 한류 기능을 갖는 초전도 케이블의 경우는 한류 임피던스를 발생시켜야 하므로 기존의 초전도 케이블과는 다른 특징을 갖는다.

초전도 한류 케이블의 종류는 동작특성에 의하여 두 가지로 분류된다. 초전도 선재에 임계전류 이상의 전류가 흐르게 되면 퀜치 (quench)현상에 의한 선재의 저항 값이 급격하게 증가하게 된다. 이러한 초전도 선의 저항을 이용한 것을 저항형 한류 케이블이라고 한다.

저항형 한류 케이블의 경우 포머의 면적을 줄여 초전도 선재의 퀜치 특성에 의해 사고 전류를 억제시키는 동작특성을 가진다. 사고 전류 투입 시 선재의 저항 증가가 케이블의 임피던스가 됨으로 큰 억제효과를 얻을 수 있다. 하지만 초전도 선재의 저항증가에 따른 온도 상승으로 퀜치 후 정상상태로 돌아오기까지 시간이 필요한 것이 단점이다.

또 다른 하나는 유도형 한류 케이블이다. 초전도 케이블은 통전층과 차폐층으로 구성되어 있는데, 정상상태에서는 통전층에 흐르는 전류가 차폐층으로 완벽하게 유도되어 케이블 외부로 자기장이 빠져나가지 않는 자기차폐 상태가 된다. 하지만 계통에 사고 발생 시 차폐층 퀜치가 발생하여 외부로 자기장이 빠져나가게 된다. 이때 케이블 외부에 자화율이 높은 물질을 둘러싸게 되면 외부로 퍼져나가는 자기장을 집속시킴으로써 유도성 임피던스가 증가하게 된다.

유도형 한류 케이블은 저항형과 반대로 케이블 외부에 철심을 설치함으로써 온도 상승에 의한 영향이 없기 때문에 


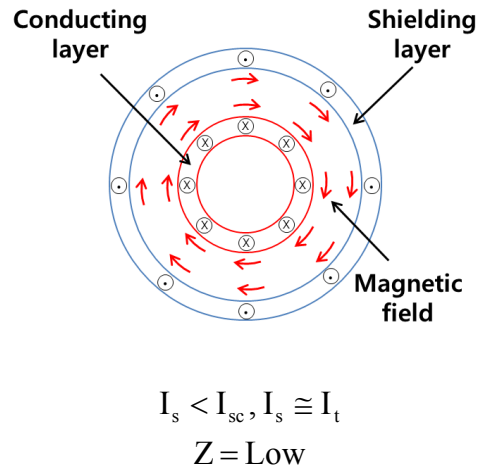

(a)

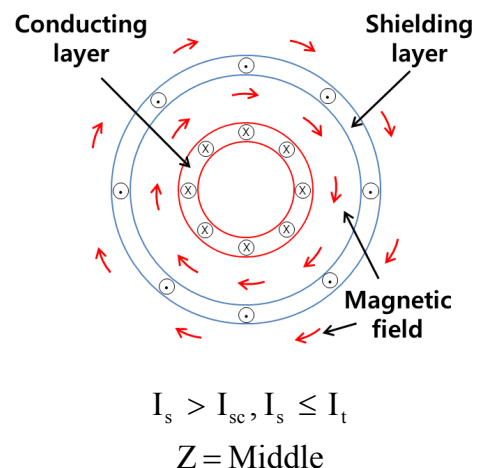

(b)

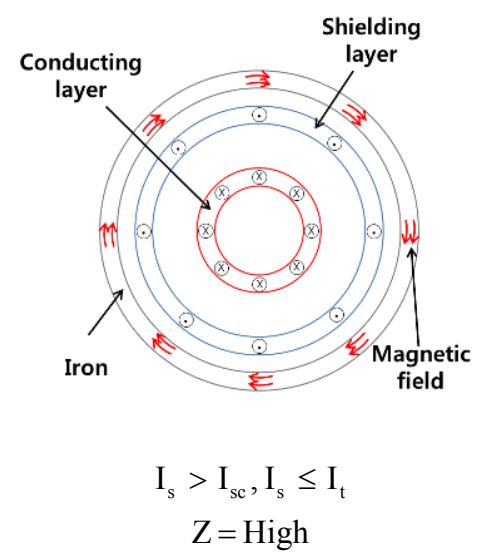

(c)

Fig. 1. Basic Concept of Inductive Current Limiting Cable.

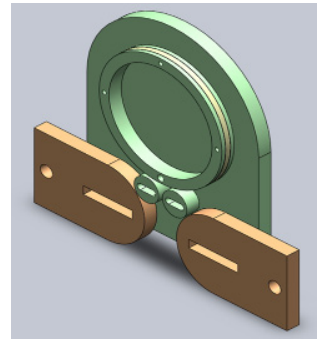

(a)

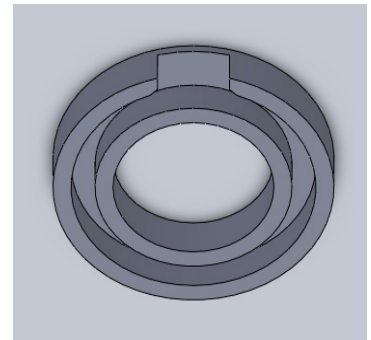

(b)
Fig. 2. (a) FRP bobbin with current terminals and (b) iron cover.

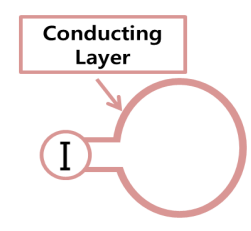

(a) Step 1

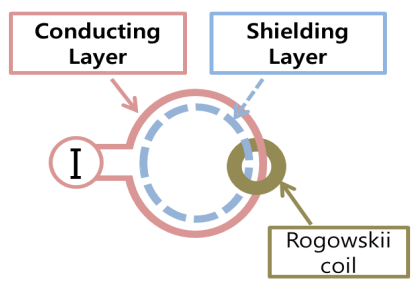

(b) Step 2

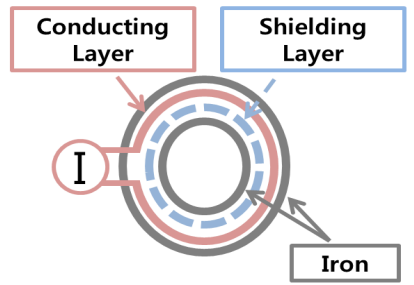

(c) Step 3

Fig. 3. Experimental procedures.

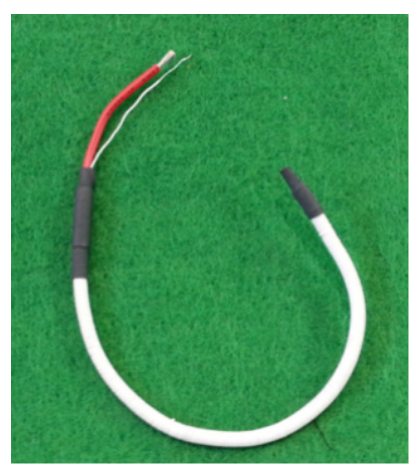

Fig. 4. Rogowski Coil for current measurement.

안정도가 높고 빠른 동작특성이 장점이지만 외부에 자화율이 높은 철심을 설치해야 하기 때문에 저항형과 비교했을 때 경제적인 측면이 단점으로 작용할 수 있다.

하지만 부하 용량의 증가로 인한 차단기 교체 및 증설에 소비되는 비용과 신속한 사고 전류 차단 등 안정성 측면에서 본다면 한류 케이블의 개발은 필요하다고 보여진다.

저항형과 유도형 한류 케이블은 서로의 단점을 보완할 수 있으므로 동시에 적용할 경우 더 큰 한류 효과를 기대할 수 있다.

본 논문에서는 유도형 한류 케이블의 기본 원리와 기초 실험을 통하여 유도형 한류 케이블의 적용 가능성을 검토하고자 한다.

\section{2. 기본 이론}

초전도 케이블은 기본적으로 포머, 통전층, 차폐층으로 구성되어 있다. 포머와 통전층은 전기적으로 연결되어 있으며, 부하전류가 흐르는 경우는 저항이 낮은 통전층으로 대부분의 전류가 흐른다. 사고 시 통전층의 임계전류(Ic) 보다 큰 전류가 흐르게 되면 퀜치가 발생하면서 통전층의 저항이 급격하게 증가하여 상대적으로 저항이 낮은 구리 포머 (former)로 전류가 우회하여 통전층을 보호하게 된다. 
TABLE I

SPECIFICATION OF SUPERCONDUCTING WIRE.

\begin{tabular}{cc}
\hline \multicolumn{2}{c}{ Superconducting Wire Specification } \\
\hline $\begin{array}{c}\text { Superconductor } \\
\text { material } \\
\text { Width } \\
\text { Thickness } \\
\text { (including copper } \\
\text { plating) } \\
\text { Substrate }\end{array}$ & GdBCO \\
Ic & $0.2 \mathrm{~mm}$ \\
Manufacturer & Hastelloy \\
\hline
\end{tabular}

TABLE II

IMPEDANCE OF CONDUCTING LAYER (STEP 1) FOR VARIOUS CURRENT.

\begin{tabular}{cccc}
\hline \multicolumn{3}{c}{ Only Conducting Layer } \\
\hline $\begin{array}{c}\text { Current } \\
{\left[\mathrm{A}_{\text {peak }}\right]}\end{array}$ & $\begin{array}{c}\text { Total } \\
\text { Impedance }\end{array}$ & $\begin{array}{c}\text { Resistive } \\
\text { Impedance }\end{array}$ & $\begin{array}{c}\text { Inductive } \\
\text { Impedance }\end{array}$ \\
100 & {$[\mu \Omega]$} & {$[\mu \Omega]$} & {$[\mu \Omega]$} \\
150 & 115 & 2.01 & 115 \\
200 & 103 & 0 & 103 \\
230 & 101 & 0 & 101 \\
250 & 107 & 1.87 & 107 \\
280 & 103 & 1.80 & 103 \\
300 & 102 & 0.86 & 102 \\
\hline
\end{tabular}

이때 통전층은 비저항이 약 $2.0 \times 10^{-8} \sim 4.0 \times 10^{-8} \Omega$ $\cdot \mathrm{m}$ 정도에서 수렴하는 상전도체가 된다[7].

초전도 케이블의 정상 운전 시 통전층에 흐르는 전류는 완벽하게 차폐층에 유도되어 그림 1 의 (a)와 같이 케이블 외부로 자기장이 누설되지 않는다. 하지만 사고 발생 시 큰 사고 전류가 유입되면, 통전층은 포머와 함께 임계전류 이상이 흐르게 되지만, 전자기 유도에 의해 전류가 발생하는 차폐층은 퀜치의 발생과 함께 통전층보다 훨씬 적은 전류만이 유도 된다. 즉, 차폐층 퀜치로 인하여 통전층 전류를 완벽하게 유도시키지 못하게 됨으로써 그림 1 의 (b) 와 같이 자기장이 초전도 케이블 외부로 누설되며 케이블 자체의 임피던스가 증가하게 된다. 특히, 그림 1 의 (c) 와 같이 케이블 외부에 자화율이 높은 물질을 둘러싸게 되면 자기장을 집속시킴으로써, 임피던스가 더욱 증가하게 된다. 이것이 유도형 한류 케이블의 기본원리로서 자기 차폐형 한류기와 유사한 동작 특성을 갖는다.

\section{3. 실험 장치 및 실험 방법}

본 논문에서는 실제 초전도 케이블을 제작하여 실험을 수행하기에 앞서 그림 2 와 같은 단순화된 실험 장치를 제작하고 유도형 한류 케이블의 기초 실험을 수행하였다. 실제 초전도 케이블을 간략화하여 통전층, 차폐층 및 철심을 모사하였는데, 원형 $\mathrm{FRP}$ 판에 차폐층을 감고 절연한 다음 그 위에 통전층을 적층하였고, 그 외부에 철심이 통전층과 차폐층을 감싸고 있는 구조이다.

차폐층은 한가닥, 통전층은 세가닥으로 제작함으로써 통전층의 임계전류를 차폐층의 임계전류보다 크게 하여 차폐층의 퀜치가 발생하더라도 통전층은 초전도 상태를 유지하도록 하였다. 통전층에서 퀜치가 발생하지 않도록 한

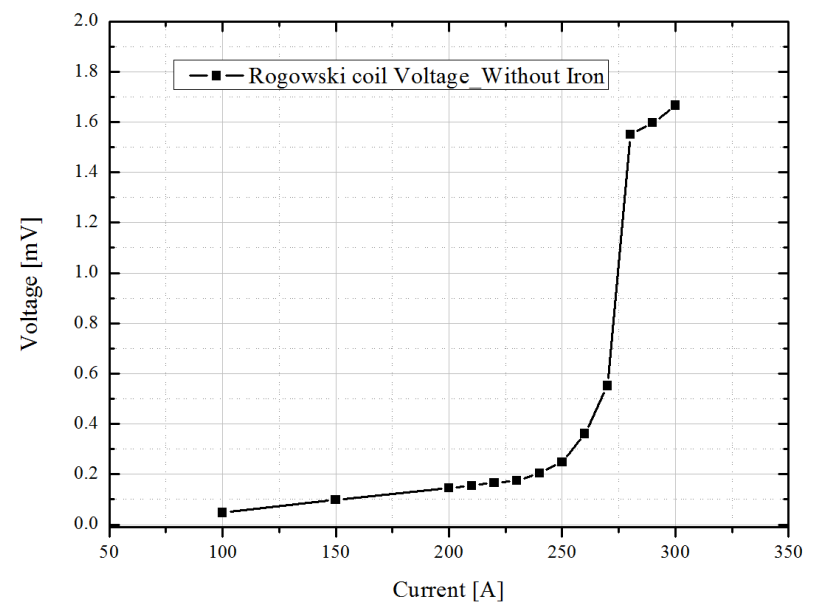

Fig. 5. Voltage of rogowski coil without iron according to current.

이유는 실험에서 저항성 임피던스의 변화를 배제하고 순수한 유도성 임피던스 변화를 측정하기 위함이다. 실험에 사용되는 선재의 사양은 표 1 과 같으며, 선재 1 가닥의 임계전류는 168 A로 측정되었다.

철심 유무에 따른 임피던스의 추가 증가를 확인하기 위하여, 3 단계로 실험을 진행하였다. 그림 3 은 단계별 개념도이다. 통전층만 있을 경우 (a), 통전층과 차폐층이 있을 경우(b), 마지막으로 통전층, 차폐층 그리고 철심이 있을 경우(c) 각각의 단계별로 전류의 크기에 따른 임피던스 변화를 확인하였다.

\section{4. 실험 결과}

먼저 전류에 따른 통전층의 임피던스 변화를 알기 위해서 그림 3 의 (a) 와 같이 통전층만 설치 후 실험한 결과 표 2 와 같은 결과를 얻을 수 있었다. 통전층의 임계전류는 3 가닥 초전도 선재를 사용함에 따라 $501 \mathrm{~A}$ 로 측정되었으며,

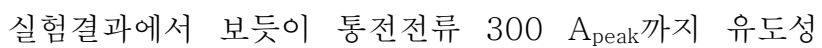
임피던스만 약 $103 \mu \Omega$ 정도로 측정되었다.

2 단계 실험에서는 통전층에 흐르는 전류가 차폐층에 유도되는지 확인하기 위하여 그림4와 같이 로고스키 코일 (Rogowski Coil) 을 제작하여 통전층과 차폐층에 의한 자장 변화율을 측정하였다. 만일 차폐층의 유도된 전류에 의하여 자장이 상쇄될수록 로고스키 코일의 전압신호가 감소하게 된다.

그림 5는 철심의 없을 경우 통전층 전류 증가에 따라 나타나는 로고스키 코일의 전압신호를 보여주고 있다. 통전층의 전류가 증가함에 따라 특정 전류 이상에서 로고스키 코일의 전압 신호가 급격하게 증가되는 것을 알 수 있으며, 이는 특정 전류 이상에서 차폐층의 퀜치로 인하여 차폐층의 유도 전류가 통전층 전류에 비해 급격히 작아지기 때문이다. 즉, 로고스키 코일 신호의 증가는 통전층 측의 임피던스 증가를 나타낸다.

실험에서 차폐층 퀜치발생 이전에도 로고스키 코일에 전압이 발생하는 것은 간략화된 실험 장치의 특성상 통전층 전류가 완벽하게 차폐층에 유도되지 않는 것으로 판단된다. 


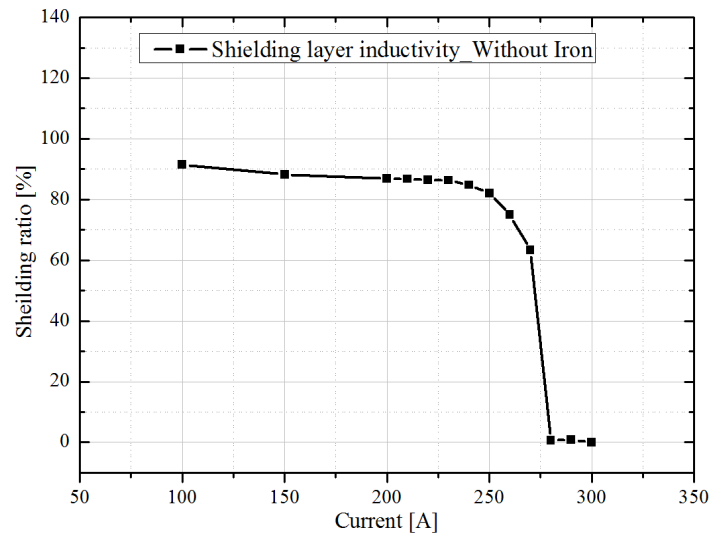

Fig. 6. Shielding ratio by induced current at the shielding layer.

로고스키 코일의 전압 신호는 로고스키 코일 안쪽에 흐르는 통전층과 차폐층 전류의 차이에 비례하기 때문에 차폐층의 전류 유도율을 유추할 수 있다. 만일 저항성분에 의한 통전층 및 차폐층의 위상 차이를 무시하고 통전층 전류 $280 \mathrm{~A}$ 이상에서 차폐층의 퀜치로 인하여 통전층 전류에 의한 신호만이 검출된다고 가정하면, 식 (1), (2), (3)으로부터 차폐층에 유도된 전류의 크기를 계산할 수 있다.

$$
\begin{aligned}
& I_{t}=K \times V_{r} \\
& K \times V_{r}=I_{t}-I_{s} \\
& I_{s}=I_{t}-K \times V_{r}
\end{aligned}
$$

여기서, $\mathrm{I}_{\mathrm{t}}$ 는 통전층 전류, $\mathrm{I}_{\mathrm{S}}$ 는 차폐층 전류, $\mathrm{V}_{\mathrm{r}}$ 은 로고스키 코일 전압, $\mathrm{K}$ 는 비례상수이다.

그림 6 은 계산된 차폐층 전류를 이용하여 나타낸 차폐층 전류 유도율을 나타낸다. 그림 6 에서 볼 수 있듯이 통전층 전류 $250 \mathrm{~A}$ 이상에서부터 차폐층의 유도율이 급격하게 떨어지기 시작하는 것을 알 수 있다. 이러한 유도율 저하는 결국 통전층의 임피던스 증가로 나타나게 된다.

그림 7은 철심 유무에 따라 통전층의 전류가 $150 \mathrm{~A}_{\mathrm{peak}}$ 및 $280 \mathrm{~A}_{\text {peak }}$ 에서 통전층에서 발생하는 전압신호를 보여준다. 철심이 없을 경우 차폐층 퀜치 이전에는 철심 유무에 따라 전압 신호가 유사하게 측정되었으나, $280 \mathrm{~A}_{\mathrm{peak}}$ 에서는

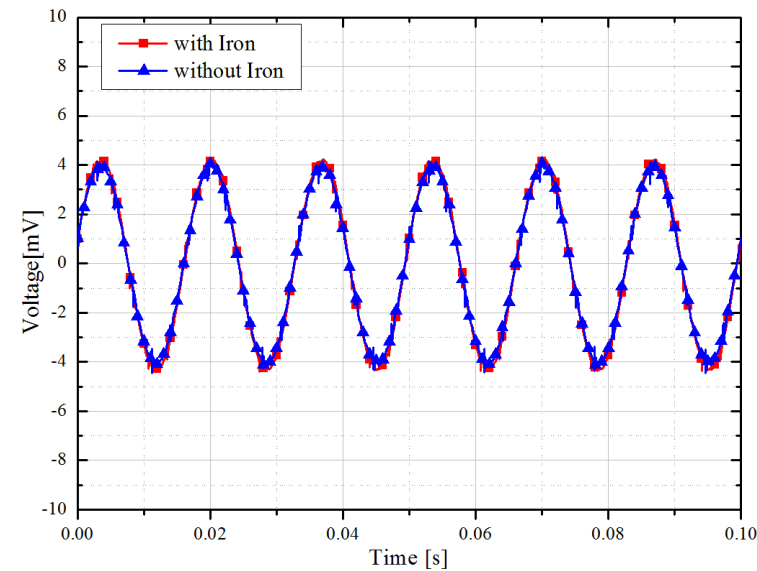

(a) $150 \mathrm{~A}_{\text {peak }}$

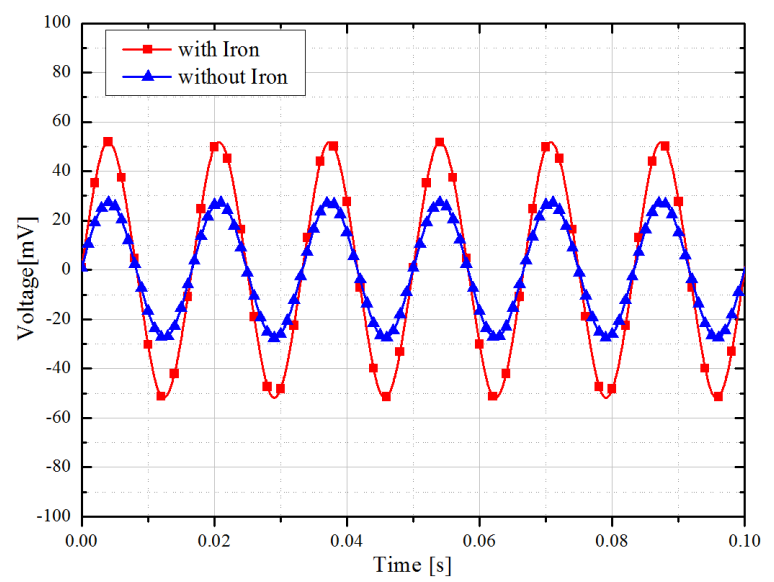

(b) $280 \mathrm{~A}_{\text {peak }}$

Fig. 7. Measured voltage of conducting layer with iron and without iron when $I_{t}$ is (a) $150 A_{\text {peak }}$, (b) $280 A_{\text {peak. }}$.

철심으로 의하여 통전층 전압이 더 크게 측정되었다. 즉, 철심에 의해서 유도성 임피던스가 더욱 증가한 것을 보여준다.

초전도 케이블의 통전층 전류 크기에 따른 임피던스 변화를 확인하기 위해 전류를 증가시키면서 통전층의 임피던스를 식 (4)와 같이 통전층의 측정된 전압신호의

\begin{tabular}{|c|c|c|c|c|}
\hline \multirow[b]{2}{*}{$\begin{array}{l}\text { Current } \\
{\left[\mathrm{A}_{\text {peak }}\right]}\end{array}$} & \multicolumn{2}{|c|}{ Without Iron (Step. 2) } & \multicolumn{2}{|c|}{ With Iron (Step. 3) } \\
\hline & $\begin{array}{c}\text { Resistive } \\
\text { Impedance }[\mu \Omega]\end{array}$ & $\begin{array}{c}\text { Inductive } \\
\text { Impedance }[\mu \Omega]\end{array}$ & $\begin{array}{c}\text { Resistive } \\
\text { Impedance }[\mu \Omega]\end{array}$ & $\begin{array}{c}\text { Inductive } \\
\text { Impedance }[\mu \Omega]\end{array}$ \\
\hline 100 & 1.58 & 25.8 & 2.56 & 29.2 \\
\hline 150 & 1.92 & 27.5 & 2.20 & 27.9 \\
\hline 200 & 2.84 & 26.7 & 3.97 & 28.3 \\
\hline 230 & 3.78 & 26.9 & 5.78 & 29.7 \\
\hline 250 & 4.93 & 28.0 & 67.7 & 168 \\
\hline 280 & 21.9 & 95.0 & 62.8 & 173 \\
\hline 300 & 23.7 & 95.2 & 63.5 & 175 \\
\hline
\end{tabular}

TABLE III

VARIATION OF RESISTIVE AND INDUCTIVE IMPEDANCE FOR DIFFERENT CURRENT AT CONDUCTING LAYER. 


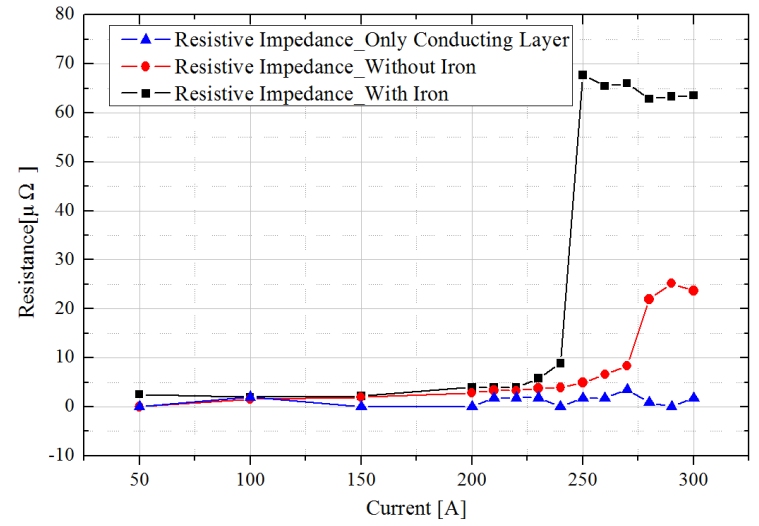

(a)

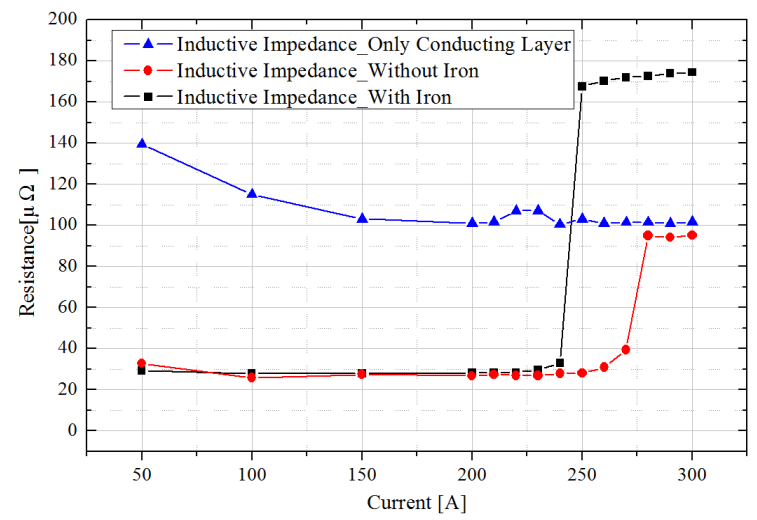

(b)

Fig. 8. Resistive impedance (a) and inductive impedance (b) for step 1,2,3 of fig. 3 .

크기 $\left(\mathrm{V}_{\mathrm{trms}}\right)$ 와 전류-전압 위상차이 $(\theta)$ 이용하여 저항성 임피던스 $\left(Z_{\text {resistive }}\right)$ 와 유도성 임피던스 $\left(Z_{\text {inductive }}\right)$ 로 분리하여 계산하였다.

$$
\begin{aligned}
& Z_{\text {total }}=\frac{\mathrm{V}_{\text {trms }}}{\mathrm{I}_{\text {trms }}} \\
& \mathrm{Z}_{\text {total }} \times \cos \theta=\mathrm{Z}_{\text {resistive }} \\
& \mathrm{Z}_{\text {total }} \times \sin \theta=\mathrm{Z}_{\text {Inductive }}
\end{aligned}
$$

표 3과 그림 8은 통전층 전류 변화에 따라 측정된 저항성 임피던스와 유도성 임피던스 변화를 보여준다.

통전층 전류가 특정 임계점 이상으로 증가함에 따라 저항성 임피던스와 유도성 임피던스가 급격하게 증가하는 것을 알 수 있었으며, 특히 차폐층 퀜치에 따라 유도성 임피던스가 크게 증가하는 것을 알 수 있었다. 통전층의 큰 임계전류로 인하여 통전층 자체에서 퀜치가 발생하지 않았음에도 저항성 임피던스가 증가한 이유는 차폐층의 퀜치에 의한 저항성분이 통전층 전압신호로 나타났기 때문이다. 특히, 철심이 있을 경우는 예상한 바와 같이 유도 성 임피던스가 더욱 크게 증가하는 것을 알 수 있었다.

그림 8 에 의하면 철심이 있을 경우 유도성 및 저항성 임피던스의 증가가 철심이 없을 경우 보다 더 낮은 통전층 전류에서 발생하는 것을 알 수 있다. 이것은 철심과 통전층 및 차폐층의 거리가 너무 근접하여 철심의 와류손에 의한 발열이 차폐층의 임계전류 감소에 영향을 미친 것으로 판단된다.

\section{5. 결 론}

본 논문에서는 유도형 한류 케이블이라는 새로운 개념의 초전도 한류 케이블에 대한 기본 이론 및 기초 실험을 진행하였다. 실제 케이블을 모사하기 위하여 통전층, 차폐층을 구성하여 임계전류 이상의 전류를 흘렸을 때 외부 철심의 유무에 따른 임피던스 변화를 측정한 결과, 철심이 없을 경우 정상상태에서는 유도성 임피던스가 $26 \mu \Omega$ 에서 쉴드층 퀜치 후 $95 \mu \Omega$ 로 4 배 정도 증가하였고, 철심이 있을 경우 $28 \mu \Omega$ 에서 $175 \mu \Omega$ 로 6 배 정도 증가하는 것을 알 수 있었다. 이는 저항형 한류 케이블에 유도형 한류 케이블을 동시에 적용할 경우 더욱 더 큰 한류 저항을 얻을 수 있음을 보여준다.

본 논문에 실제 케이블 형태가 아닌 단순화된 실험 장치를 통하여 유도형 한류 케이블의 적용 가능성을 검토하였으며, 추후 실제 케이블과 유사한 모델 케이블을 제작하여 정밀한 실험을 통해 그것을 증명하고 유도형 한류 케이블의 효과를 확인할 계획이다.

\section{ACKNOWLEDGMENT}

This work was supported by the National Research Foundation of Korea (NRF) grant funded by the Korea government (MEST) (No. 2011-0031515)

\section{REFERENCES}

[1] Seokho Kim, Kideok Sim, Jeonwook Cho, Hyun-man Jang, Minwon Park, "AC Loss Analysis of HTS Power Cable With RABiTS Coated Conductor," IEEE Trans. on Appl. Supercon., vol. 20, no. 3, pp. 2130-2133, 2010.

[2] Jin Bae Na, Jae Young Jang, Young Jin Hwang, Hyoungku Kang, Tae Kuk Ko, "Study on the High Temperature Superconductor for applying resistive Superconducting Fault Current Limiter," Korean Institute of Electrical Engineers, vol.60, no.7, pp. 1013-1014, 2011.

[3] Jae-Ho Kim, Minwon Park, Mohd. Hasan Ali, Jeonwook Cho, Kideok Sim, Seokho Kim, Hae-Joon Kim, Sang Jin Lee, In_Keun Yu, "Investigation of the Over Current Characteristics of HTS Tapes Considering the Application for HTS Power Devices", IEEE Trans. on Appl. Supercon., vol. 18, no. 2, pp. 1139-1142, 2008.

[4] Tae Kuk Ko, "Development of Three Phase $6.6 \mathrm{kV} / 200 \mathrm{~A}$ Class Inductive Superconducting Fault Current Limiter" Superconductivity and cryogenics, vol .6, no.2, pp.16-20, 2004.

[5] J.-S. Kim, J.-F. Moon, S.-H. Lim, J.-C. Kim, "Study on Selection of SFCL's Impedance for Protective coordination with Overcurrent Relay in a Distribution System," IEEE T\&D Conference and Exhibition, pp. 1-4, 2009.

[6] S. Kim, Jae-Ho Kim, J. Cho, K. Sim and et al, "Investigation on the Stability of HTS Power Cable under Fault Current Considering Stabilizer," IEEE Trans. on Appl. Supercon., vol. 17, no. 2, pp. 1676-1679, 2007.

[7] K. D. Sim, J. W. Cho, J. H. Bea, H. J. Kim, S. H. Kim, K. C. Seong, J. H. Kim, H, M. Jang, and C. Y. Lee, "Design of HTS Transmission Cable With cu Stabilizer," IEEE Trans. on Appl. Supercon., vol. 16, no. 2, pp. 1622-1625, 2006. 